\title{
Quality and Authenticity of Metformin Tablets Circulating on Japanese Websites
}

\author{
Shu Zhu ${ }^{1} \cdot$ Naoko Yoshida $^{2} \oplus \cdot$ Hirohito Tsuboi $^{3} \cdot$ Ryo Matsushita $^{3} \cdot$ Kazuko Kimura $^{1}$
}

Received: 25 November 2020 / Accepted: 26 January 2021 / Published online: 17 February 2021

(c) The Author(s) 2021

\begin{abstract}
Background Low-quality medicines and falsified medicines represent long-standing problems in developing countries. In Southeast Asia, the circulation of low-quality diabetes drugs (metformin) has been confirmed. It is possible that low-quality metformin has entered Japan via personal import through the Internet. This study evaluated the pharmaceutical quality and authenticity of metformin tablets obtained via the Internet in Japan.

Methods In total, 33 samples of 500-mg metformin tablets and 7 samples of extended-release/sustained-release tablets (500, 750 , and 1,000 mg) were purchased via personal import in January 2017. Confirmation of a prescription was never requested purchase. The obtained samples were subjected to visual observations and authenticity investigations. Additionally, quantitative analysis, content uniformity and dissolution tests were performed using HPLC-PDA.

Results Our authenticity investigations revealed that seven samples were genuine products, whereas the authenticity of the remaining 33 samples was unclear. Referring to United States Pharmacopeia 2014 for validation, four samples failed quality testing, five samples failed content uniformity testing, and two samples failed dissolution testing.

Conclusions Our findings illustrate that metformin tablets of poor-quantity and unregistered/unlicensed doses are available online and that it is important to increase consumer awareness about the presence of these medicines on the Internet to prevent the purchase of substandard medicines.
\end{abstract}

Keywords Poor-quality medicine $\cdot$ Metformin $\cdot$ Quality $\cdot$ Personal import $\cdot$ Internet

\section{Introduction}

Diabetes mellitus, a metabolic disorder characterized by hyperglycemia, seriously affects human health and quality of life [1]. The World Health Organization (WHO) estimated that 108 million people had diabetes in 1980, and this number is projected to increase to 693 million by $2045[2,3]$.

Naoko Yoshida

naoko@p.kanazawa-u.ac.jp

1 Graduate School of Medical Sciences, Medi-Quality Security Institute, Kanazawa University, Kakuma-machi, Kanazawa 920-1192, Japan

2 AI Hospital/Macro Signal Dynamics Research and Development Center, Institute of Medical, Pharmaceutical and Health Sciences, Kanazawa University, Kakuma-machi, Kanazawa, Ishikawa 920-1192, Japan

3 Clinical Pharmacy and Healthcare Sciences, Faculty of Pharmacy, Institute of Medical, Pharmaceutical and Health Sciences, Kanazawa University, Kakuma-machi, Kanazawa 920-1192, Japan
Preventing and managing diabetes have become major public health challenges worldwide.

Metformin (1,1-metformin) is a biguanide derivative and is the most commonly used treatment for type 2 diabetes (T2D) [4]. Various studies have illustrated that metformin has roles in preventing diabetes, protecting the nervous and cardiovascular systems, and treating polycystic sputum syndrome and cancer in addition to T2D [4-7]. In the future development of medical treatment, metformin will play a particularly important role.

However, even if efficacious medicines are developed, patients may not benefit in some cases because of the existence of substandard and falsified medicines. For example, the active components of substandard medicines do not reach the therapeutic level, and falsified medicines may not contain therapeutic components. WHO defines "substandard and falsified medical products" as follows: "a) substandard (also called "out of specification"): these are authorized medical products that fail to meet either their quality standards or specifications, or both; b) unregistered/unlicensed: 
medical products that have not undergone evaluation and/or approval by the National or Regional Regulatory Authority for the market in which they are marketed/distributed or used, subject to permitted conditions under national or regional regulation and legislation; c) falsified: medical products that deliberately/fraudulently misrepresent their identity, composition, or source" [8]. It was stated in many reports that falsified and substandard medicines are available in developing countries [9-12]. However, falsified and substandard medicines appear to be available globally [13]. People in the United States, Europe, and Australia are generally aware that online pharmacies form part of the official medicine distribution channels, and controlled medicines require a prescription [14]. However, with the increasing consumption of prescription drugs, unlicensed, substandard, and falsified medicines with dubious medical claims are advertised and sold illegally by many rogue online pharmacies [15]. It is illegal to sell prescription medicines online in Japan. However, the personal import of prescription medicines is not illegal in the country [16]. Although the government does not encourage citizens to import drugs, it cannot prohibit this activity. In a research report from 2016, no more than $1 \%$ of agencies advertising medicine for personal import were in compliance with Japanese law [17]. The supply chain of pharmaceuticals is managed properly in Japan, but the personal import of medicines via the Internet might allow substandard and falsified medicines to enter the country. In previous studies, we found that falsified weightloss and erectile dysfunction drugs containing no active pharmaceutical ingredient [18-20]. Even when drugs are not falsified, the quality of a drug produced by the same manufacturer can differ according to the place of origin and market [21] In Southeast Asia, the circulation of low-quality metformin has been confirmed [12]. However, the quality and authenticity of metformin circulating on the Internet remain unclear.

To prevent the use of substandard and falsified medicines, this research examined the quality and authenticity of metformin tablets available online.

\section{Materials and Methods}

\section{Sample Collection}

We used Google Japan to identify purchase websites using the keyword search "Metformin personal import" in Japanese (メホルミン個人輸入). Among the purchase websites that could be identified using Google Japan, all sites that permitted payment via bank transfer were targeted. We performed Internet searches between October 27, 2016 and November 9, 2016.
Based on the website search, 500-mg metformin tablets were sold on most websites. Therefore, 500-mg metformin tablets were purchased in this study. Additionally, we purchased sustained-released/extended-release tablets containing 500,750 , or $1,000 \mathrm{mg}$ of metformin. The number of units purchased per site exceeded 60 tablets. Additionally, when different packaging types (boxes and bottles) were available on the same site, both were purchased (Table 1).

There are two registered/licensed doses of metformin tablets in Japan: 250 and $500 \mathrm{mg}$. Sustained-release tablets/ extended-release tablets are not approved in the country. In the United States, metformin is available at five registered/ licensed doses for normal formulations $(500,625,750,850$, and $1,000 \mathrm{mg}$ ) and three doses for sustained-release tablets/ extended-release formulations $(500,750$, and 1,000 mg).

\section{Visual Observations}

In the visual observation of the purchased products, abnormalities such as an inappropriate description, color, stain, or scratch on the packaging or tablets were recorded. The packaging and inserts were stored as scan data, and the pressthrough package (PTP) sheet and aluminum-plastic composite film package (APCFP) were stored as a photograph.

\section{Purchase Price}

We calculated the purchase price of each tablet from the Internet, excluding the shipping and import fees. The standard price for metformin prescribed under the Japanese Health Insurance System is 16.7 yen/tablet for the branded 500-mg product and 9.6-9.9 yen/tablet for generic products. The price of metformin per tablet in Japan (As of August 2, 2017) was compared with that online.

\section{Authenticity Investigation}

A questionnaire with photographs of purchased products was sent to each manufacturer or distributor on August 14, 2017. The questionnaires contained the results of the appearance observations, authenticity tests, product names, active pharmaceutical ingredient (API), doses, forms, manufacturer name and address, batch/lot number, manufacturing license number, logo, manufacturing date, product expiration date, and a description of the outer box and instructions. We also asked whether the product was allowed to be manufactured or sold in the manufacturing country and if any countermeasures had been taken against falsified products.

\section{Details Given on the Website}

We recorded whether the website provided the following details required by the Act on Specified Commercial 
Table 1 List of samples collected

\begin{tabular}{|c|c|c|c|c|c|c|c|c|}
\hline Sample No & Site No & $\begin{array}{l}\text { Stated product } \\
\text { name }\end{array}$ & $\begin{array}{c}\text { Dose } \\
(\mathrm{mg}) / \text { number of } \\
\text { pills }\end{array}$ & $\begin{array}{l}\text { Packaging and } \\
\text { language }\end{array}$ & $\begin{array}{l}\text { Labeled manu- } \\
\text { facturing and/ } \\
\text { or distributing } \\
\text { country }\end{array}$ & $\begin{array}{l}\text { Shipping } \\
\text { country }\end{array}$ & $\begin{array}{l}\text { Package } \\
\text { insert and } \\
\text { language }\end{array}$ & Authenticity \\
\hline 1 & 1 & GLYCIPHAGE & $500 / 60$ & PTP/English & India & Singapore & None & Unknown \\
\hline 2 & 2 & ZOMET & $500 / 100$ & Box/English & India & Singapore & None & Unknown \\
\hline 3 & 3 & GLYCOMET & $500 / 100$ & PTP/English & India & Singapore & None & Unknown \\
\hline 4 & 4 & $\begin{array}{l}\text { GLU- } \\
\text { COPHAGE }\end{array}$ & $500 / 100$ & APCFP/English & Unknown & Thailand & None & Unknown \\
\hline 5 & & Metformin & $500 / 56$ & Box/English & $\begin{array}{l}\text { United King- } \\
\text { dom }\end{array}$ & Singapore & Yes/English & Unknown \\
\hline 6 & & $\begin{array}{l}\text { APO-Met- } \\
\text { formin } 500\end{array}$ & $500 / 100$ & Box/English & Unknown & Singapore & None & Genuine \\
\hline 7 & 5 & $\begin{array}{l}\text { APO-Met- } \\
\text { formin } 500\end{array}$ & $500 / 100$ & Box/English & $\begin{array}{l}\text { United King- } \\
\text { dom }\end{array}$ & Singapore & None & Genuine \\
\hline 8 & 6 & $\begin{array}{l}\text { APO-Met- } \\
\text { formin } 500\end{array}$ & $500 / 100$ & Box/English & Unknown & Singapore & None & Genuine \\
\hline 9 & 7 & Metformin & $500 / 100$ & Bottle/English & India & America & Yes/English & Unknown \\
\hline 10 & 8 & Metformin & $500 / 56$ & Box/English & $\begin{array}{l}\text { United King- } \\
\text { dom }\end{array}$ & Singapore & Yes/English & Unknown \\
\hline 11 & 9 & $\begin{array}{l}\text { Metformin- } \\
\text { GPO }\end{array}$ & $500 / 100$ & APCFP/English & Thailand & Thailand & Yes/English & Unknown \\
\hline 12 & & Siamformet & $500 / 100$ & $\begin{array}{c}\text { Box/English } \\
\text { and Thai }\end{array}$ & Thailand & Thailand & Yes/Thai & Unknown \\
\hline 13 & 10 & Metformin & $500 / 112$ & Box/English & $\begin{array}{l}\text { United King- } \\
\text { dom }\end{array}$ & Singapore & Yes/English & Unknown \\
\hline 14 & & $\begin{array}{l}\text { APO-Met- } \\
\text { formin } 500\end{array}$ & $500 / 100$ & Box/English & $\begin{array}{l}\text { United King- } \\
\text { dom }\end{array}$ & Singapore & None & Genuine \\
\hline 15 & & ZOMET & $500 / 100$ & Box/English & India & Singapore & None & Unknown \\
\hline 16 & 11 & ZOMET & $500 / 100$ & Box/English & India & Singapore & None & Unknown \\
\hline 17 & 12 & GLYCIPHAGE & $500 / 60$ & PTP/English & India & $\begin{array}{l}\text { Singapore/ } \\
\text { Hong Kong }\end{array}$ & None & Unknown \\
\hline 18 & 13 & Glucophage & $500 / 200$ & PTP/Chinese & France & Taiwan & Yes/Chinese & Unknown \\
\hline 19 & 14 & Okamet-500 & $500 / 200$ & PTP/English & India & India & None & Genuine \\
\hline 20 & 15 & GLYCOMET & $500 / 100$ & Box/English & India & Singapore & None & Unknown \\
\hline 21 & 16 & METCHEK & $500 / 1000$ & Bottle/English & New Zealand & Hong Kong & None & Unknown \\
\hline 22 & & GLYCIPHAGE & $500 / 60$ & PTP/English & India & Hong Kong & None & Unknown \\
\hline 23 & 17 & Glucophage & $500 / 280$ & PTP/English & Unknown & Malaysia & None & Unknown \\
\hline 24 & & $\begin{array}{l}\text { Metformin } \mathrm{HCl} \\
\text { BP } 500\end{array}$ & $500 / 250$ & PTP/English & Unknown & Malaysia & None & Unknown \\
\hline 25 & 18 & $\begin{array}{l}\text { GLU- } \\
\text { COPHAGE }\end{array}$ & $500 / 60$ & APCFP/English & Unknown & Thailand & None & Unknown \\
\hline 26 & 19 & $\begin{array}{l}\text { APO-Met- } \\
\text { formin } 500\end{array}$ & $500 / 100$ & Box/English & Unknown & Singapore & None & Genuine \\
\hline 27 & & Metformin & $500 / 56$ & Box/English & $\begin{array}{l}\text { United King- } \\
\text { dom }\end{array}$ & Singapore & Yes/English & Unknown \\
\hline 28 & & ZOMET & $500 / 100$ & Box/English & India & Singapore & None & Unknown \\
\hline 29 & 20 & GLYCIPHAGE & $500 / 60$ & PTP/English & India & Hong Kong & None & Unknown \\
\hline 30 & 21 & Metformin & $500 / 100$ & PTP/English & Unknown & Thailand & None & Unknown \\
\hline 31 & 22 & Glucophage & $500 / 100$ & APCFP/English & Unknown & Thailand & None & Unknown \\
\hline
\end{tabular}


Table 1 (continued)

\begin{tabular}{|c|c|c|c|c|c|c|c|c|}
\hline Sample No & Site No & $\begin{array}{l}\text { Stated product } \\
\text { name }\end{array}$ & $\begin{array}{c}\text { Dose } \\
(\mathrm{mg}) / \text { number of } \\
\text { pills }\end{array}$ & $\begin{array}{c}\text { Packaging and } \\
\text { language }\end{array}$ & $\begin{array}{c}\text { Labeled manu- } \\
\text { facturing and/ } \\
\text { or distributing } \\
\text { country }\end{array}$ & $\begin{array}{l}\text { Shipping } \\
\text { country }\end{array}$ & $\begin{array}{l}\text { Package } \\
\text { insert and } \\
\text { language }\end{array}$ & Authenticity \\
\hline 32 & 23 & $\begin{array}{l}\text { メホルミン塩 } \\
\text { 酸塩錠500 } \\
\text { mg (English } \\
\text { translation: } \\
\text { Metformin } \\
\text { Hydrochlo- } \\
\text { ride } 500 \mathrm{mg} \text { ) }\end{array}$ & $500 / 50$ & PTP/Japanese & Japan & Singapore & Yes/Japanese & Genuine \\
\hline 33 & 24 & $\begin{array}{l}\text { Metformin } \\
\text { Hydrochlo- } \\
\text { ride Tablets } \\
\text { USP }\end{array}$ & $500 / 100$ & Bottle/English & India & America & Yes/English & Unknown \\
\hline 34 & 7 & $\begin{array}{l}\text { Metformin } \\
\text { Hydro- } \\
\text { chloride } \\
\text { Extended- } \\
\text { Release } \\
\text { Tablets, USP }\end{array}$ & $500 / 60$ & Bottle/English & Canada & America & None & Unknown \\
\hline 35 & 3 & GLYCIPHAGE & $500 / 60$ & Bottle/English & India & India & None & Unknown \\
\hline 36 & & $\begin{array}{l}\text { Metformin } \\
\text { Hydro- } \\
\text { chloride } \\
\text { Extended- } \\
\text { Release } \\
\text { Tablets, USP }\end{array}$ & $1,000 / 60$ & Bottle/English & India & India & None & Unknown \\
\hline 37 & 17 & Glucophage & $500 / 60$ & Box/English & France & Malaysia & Yes/English & Unknown \\
\hline 38 & 24 & $\begin{array}{l}\text { Metformin } \\
\text { Hydro- } \\
\text { chloride } \\
\text { Extended- } \\
\text { Release } \\
\text { Table, USP }\end{array}$ & $750 / 100$ & Bottle/English & India & America & Yes/English & Unknown \\
\hline 39 & & $\begin{array}{l}\text { Metformin } \\
\text { Hydro- } \\
\text { chloride } \\
\text { Extended- } \\
\text { Release } \\
\text { Table, USP }\end{array}$ & $500 / 100$ & Bottle/English & India & America & Yes/English & Unknown \\
\hline 40 & 15 & Metsmall & $500 / 100$ & Box/English & India & Singapore & None & Unknown \\
\hline
\end{tabular}

$P T P$ press-through package, $A P C F P$ aluminum-plastic composite film package

Transactions [22] for personal import into Japan: name of a representative or responsible person, name of the business, address of the business, telephone number, product price, shipping fee, payment time, product delivery time, payment method, and conditions of return.

Additionally, we recorded the status of compliance with the following details required by the Act on Securing Quality, Efficacy and Safety of Products Including Pharmaceuticals and Medical Devices (Japanese Law Translation) [23]: a statement recommending consultation with a doctor or pharmacist, a description of personal importation, a statement outlining any purchase quantity limit, and a description of the medicine (e.g., name of the API, images that clearly distinguish products, or a description of the medicine's use, dose, efficacy, and side effects), and the contact for medicine consultation.

\section{Materials}

Metformin hydrochloride, heptanesulfonate, acetonitrile, amoxicillin trihydrate, and methanol (FUJIFILM Wako Pure Chemical Corporation, Osaka, Japan) were used for the analysis. We obtained potassium sodium chloride, phosphoric acid, potassium dihydrogen phosphate, and $0.2 \mathrm{~N}$ sodium hydroxide from Nacalai Tesque, Inc. (Kyoto, Japan). All 
other chemicals were commercially available and of analytic grade.

\section{Pharmacopeia Test of the Tablets}

\section{Quantitative Assay}

Quantitative assay was conducted with reference to United States Pharmacopeia 37 (USP 37) [24] using the LC-10 AD system (Shimadzu, Kyoto, Japan) with a photodiode array detector. The column was Shim-pack CLC-ODS (M) $5 \mathrm{~mm}$ $(4.6 \mathrm{~mm} \times 25 \mathrm{~cm}$, Shimadzu), and the column temperature was maintained at $30{ }^{\circ} \mathrm{C}$ using a column oven (CTO-20AC, Shimadzu). The buffer was composed of $0.5 \mathrm{~g} / \mathrm{L}$ heptanesulfonate and $0.5 \mathrm{~g} / \mathrm{L}$ sodium chloride in water. The $\mathrm{pH}$ was adjusted to $3.85 \pm 0.30$ with phosphoric acid. We used a mobile phase of acetonitrile: $\mathrm{pH} 3.85$ buffer (1:9). The mobile phase flow rate was $0.9 \mathrm{~mL} / \mathrm{min}$, and the injection volume was $10 \mu \mathrm{L}$. The detection wavelength range was 232 (metformin hydrochloride tablets) or $218 \mathrm{~nm}$ (metformin hydrochloride sustained-release tablets). Measurements for metformin hydrochloride were performed using 10 tablets for each product. Identification of the contained components was performed by confirming that the retention time of the component matched that of the standard reagent and that the UV spectra coincided. In the first stage, the following tolerances were regarded as passing: $95.0 \% \leq \mathrm{MEF} \leq 105.0 \%$ for normal tables [24] and $90.0 \leq \mathrm{MEF} \leq 110.0 \%$ for sustainedrelease tablets [24]. If the samples did not reach these tolerances, they were assayed in the second stage.

\section{Content Uniformity (CU) Testing}

CU testing was conducted with reference to USP 37 [24]. In the first stage, a sample acceptance value $(\mathrm{AV}) \leq 15$ was regarded as passing for both normal and sustained-release tablets [24]. If the samples did not reach this tolerance, they were assayed in the second stage. If an $\mathrm{AV}$ of $<73.88$ or $>126.88$ was observed for one tablet, it was judged as a permanent fail in the first stage [24].

\section{Dissolution Testing}

We performed dissolution testing using a dissolution apparatus (NTR-VS6P; Toyama Sangyo Co. Ltd., Osaka, Japan) according to USP 37 [24]. Six tablets were measured per product. For normal tablets in the first stage, a tolerance of $\geq 75 \%$ of the labeled amount of metformin at a dissolution time of 45 min was regarded as passing in the dissolution test [24]. For 500-mg sustained-release tablets, the following tolerances were regarded as passing: $20 \%-40 \%$ for $1 \mathrm{~h}$; $45 \%-65 \%$ for $3 \mathrm{~h}$; and $\geq 80 \%$ for $10 \mathrm{~h}$ [24]. Additionally, the dissolution rates of 750- and 1,000-mg sustained-release tablet were determined to be appropriate as follows: $20 \%-40 \%$ for $1 \mathrm{~h} ; 35 \%-55 \%$ for $2 \mathrm{~h} ; 65 \%-85 \%$ for $6 \mathrm{~h}$; and $\geq 85 \%$ for $10 \mathrm{~h}$ [24]. If the samples did not reach these tolerances, they were assayed in the second stage.

\section{Results}

\section{Sample Collection}

In total, 40 samples were obtained from 24 websites. We purchased 33 normal 500-mg tablets and 7 extended/ sustained-release tablets (500 mg, five; $750 \mathrm{mg}$, one, and $1,000 \mathrm{mg}$, one). Table 1 lists the samples collected. Among the 33 normal tablets, five were branded products, and 28 were generic products. No prescription was required at any website.

\section{Visual Observations}

Among the 500-mg tablets, one sample (No. 32) was from Singapore (Table 1), but the product PTP sheet and package insert were written in Japanese. The manufacturer listed in the package insert was "Towa Pharmaceutical Co., Ltd." The sample had no box, and the expiration date and lot number were affixed to the package insert, which appeared to be a copy of that part of the outer box. The expiration date and lot number were not usually described in the package insert of the product sold in Japan (metformin hydrochloride tablet $500 \mathrm{mg}$ MT "Towa").

For another 500-mg sample (No. 12), the box indicated that the dose was $500 \mathrm{mg}$, but the insert stated a dose of $850 \mathrm{mg}$. From the measurement of the ingredient content, this product was considered a 500-mg tablet (Table 4).

The packaging form of the samples can be divided into four types (Table 1), namely the PTP sheet, APCFP, box (PTP sheet in a box), and bottle. Two of the PTP sheets were written in Japanese and Chinese, respectively, and all other packaging types were written in English. The package insert was enclosed for 12 of 40 samples. Among the 12 samples, the insert was written in Japanese, English, Chinese, and Thai for one, nine, one, and one product, respectively.

Among all 40 samples, only the manufacturing country was printed on a label for 29 samples and only the distributing country for one sample, whereas this information was not listed for the remaining 10 samples. The identified manufacturing countries included India, the United Kingdom, France, Thailand, Japan, and Canada, and the distribution country stated for a sample was New Zealand. Approximately $48 \%$ of samples were shipped from Singapore, and the other shipping countries were Thailand, Taiwan, the United States, India, Hong Kong, and Malaysia. One sample (No. 17) included parcel posts for both Singapore and Hong 
Kong (Table 1). Although the sender addresses differed, the sender was the same on both parcel posts. Because the lot numbers of this sample were identical, we defined it as a single sample.

Regarding the appearance of the tablets, sample No. 40 had a blue stain, sample No. 28 had a yellow stain, and sample No. 16 had a physical crack.

\section{Purchase Price}

Metformin is included in the National Health Insurance drug price list in Japan. Regarding price, the price of metformin 500-mg tablets was 16.7 yen/tablet for the branded product and 9.6-9.9 yen/tablet for the generic product at the time of purchase. The prices of metformin tablets purchased in this study are presented in Fig. 1. The average prices of the branded and generic 500-mg products online were $(33.3 \pm 7.4(n=5)$ and $31.4 \pm 3.1$ yen/tablet $(n=28)$, respectively. The online prices of the branded and generic 500-mg sustained-release tablets were $65(n=1)$ and $44.8 \pm 9.4$ yen/ tablet $(n=4)$, respectively. The online prices of 750 - and 1,000-mg sustained-release tablets were $54(n=1)$ and 62 yen/tablet $(n=1)$, respectively.

\section{Authenticity}

A response was received from "CIPLA LTD" on August 21, 2017. We received an answer from Towa Pharmaceutical Co., Ltd. on October 24, 2017. A response was received from the "Apotex Pty Ltd" on September 8, 2017. Based on the responses, seven products were confirmed to be genuine. We sent reminders to other manufactures again in April 2018, but no response was received; thus, the authenticity of the other 33 products remains unknown.

\section{Evaluation of Website Details}

According to the Specified Commercial Transactions Law, certain details must be provided on commercial websites (Table 2). However, only 6 of the 24 websites from which products were purchased listed all of the necessary details. We checked whether the products met the requirements of the Act on Securing Quality, Efficacy

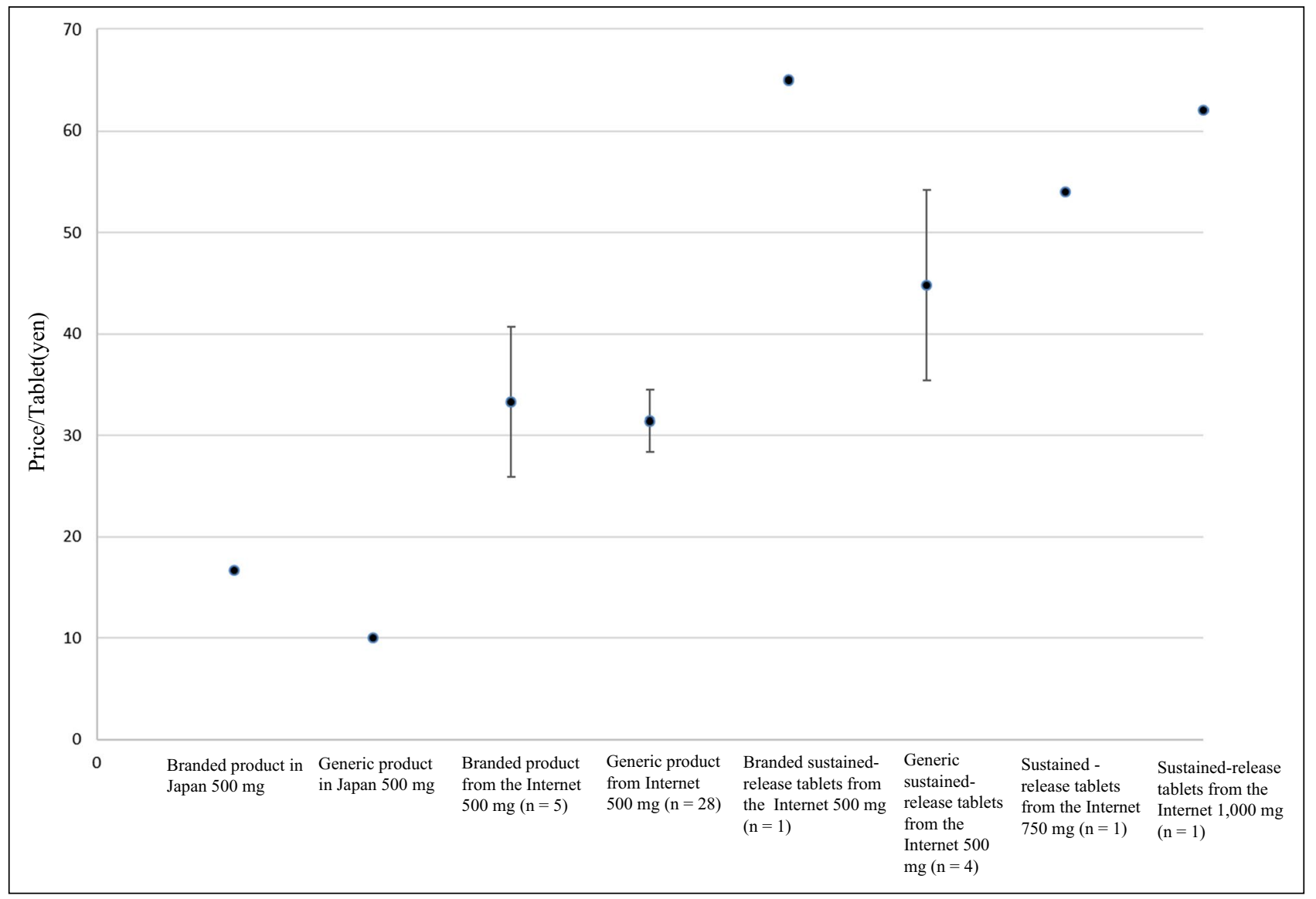

Fig. 1 Average price per tablet (shipping fee excluded) for metformin tablets: comparison of the price of metformin tablets in Japan (branded and generic) and purchased online 
Table 2 Proportions of websites that met the requirements of the Specified Commercial Transactions Law

\begin{tabular}{ll}
\hline \multicolumn{1}{c}{ Required detail } & $\begin{array}{c}\text { Number of } \\
\text { websites } \\
(\%)\end{array}$ \\
\hline Name of a representative or responsible person & $13(54.0)$ \\
Name of the business & $17(71.0)$ \\
Address of the business & $19(79.0)$ \\
Telephone number & $19(79.0)$ \\
Product price & $24(100.0)$ \\
Shipping fee & $21(88.0)$ \\
Payment time & $15(63.0)$ \\
Product delivery time & $22(92.0)$ \\
Payment method & $22(92.0)$ \\
Conditions for return & $21(88.0)$ \\
\hline
\end{tabular}

$n=24$ websites

and Safety of Products Including Pharmaceuticals and Medical Devices (Table 3). Among the 24 websites, 22 did not appear to adhere fully with the recommendations for personal drug importation.

\section{Pharmacopeia Test of the Tablets}

\section{Quantification of Metformin in the Tablets}

Table 4 presents the results of quantitative analysis of metformin hydrochloride samples. In quantitative analysis, 36 samples $(90 \%)$ passed. The contents of sample Nos. 15, 21, and 29 (all 500-mg tablets) were $94.5 \pm 1.53$, $93.6 \pm 5.71$, and $107.0 \pm 2.75 \%$, respectively. The content of the incompatible sustained-release tablet No. 36 was $116.71 \pm 16.52 \%$, which exceeded the tolerance limit of the Pharmacopeia. [24].

\section{CU Testing}

In total, 35 samples (87.5\%) passed CU testing (Table 4). Among the failing samples, AV ranged 16.6-54.9.

\section{Dissolution Testing}

Table 4 presents the results of dissolution testing for the samples. In total, 38 samples (95\%) passed. Two samples that failed testing were sustained-release/extended-release tablets. The dissolution rate of tablet No. 40 (500-mg sustainedrelease tablet) was $68.6 \pm 3.25 \%$ at $3 \mathrm{~h}$, which exceeded the tolerance limit. The dissolution rate of tablet No. $36(1,000-$ mg extended-release tablet) was $87.03 \pm 6.28 \%$ at $6 \mathrm{~h}$, which also exceeded the tolerance limit.

\section{Discussion}

In this study, we found that 4 of 24 websites (17\%) for personal import agencies advertised the API, efficacy, and names of products (metformin hydrochloride sustainedrelease tablet) not approved in Japan, although article 68 of the Act on Securing Quality, Efficacy and Safety of Products Including Pharmaceuticals and Medical Devices prohibits advertising of unregistered/unlicensed medicines, and advertisements related to the name, manufacturing method, efficacy, effect, or performance of unregistered/unlicensed medicine are also prohibited [23].

Additionally, it has become clear that unregistered/unlicensed medicines can be obtained without a prescription. Unregistered/unlicensed medicines available online have not been evaluated for safety in Japan, and thus, they are not eligible for the medicine side effects relief system [25]. Personally imported drugs carry certain health risks. Additionally, the Ministry of Health, Labour and Welfare of Japan has been providing information and warnings about the personal
Table 3 Proportions of websites that met the requirements of the Act on Securing Quality, Efficacy and Safety of Products Including Pharmaceuticals and Medical Devices

\begin{tabular}{lc}
\hline \multicolumn{1}{c}{ Required detail } & $\begin{array}{c}\text { Number of } \\
\text { websites } \\
(\%)\end{array}$ \\
\hline A statement recommending consultation with a doctor or pharmacist & $7(29.0)$ \\
A description of personal importation & $17(70.0)$ \\
A statement on the purchase quantity limit & $16(67.0)$ \\
Description of unapproved medicines or ethical medicines & $24(100.0)$ \\
The name of the product & $24(100.0)$ \\
A photograph of the product & $22(92.0)$ \\
Dose of the active ingredient & $10(41.0)$ \\
Description of the active pharmaceutical ingredient & $13(54.0)$ \\
Description of potential side effects & $6(25.0)$ \\
\hline
\end{tabular}

$n=24$ websites 
Table 4 Results of quantity, content uniformity, and dissolution testing of metformin hydrochloride tablets

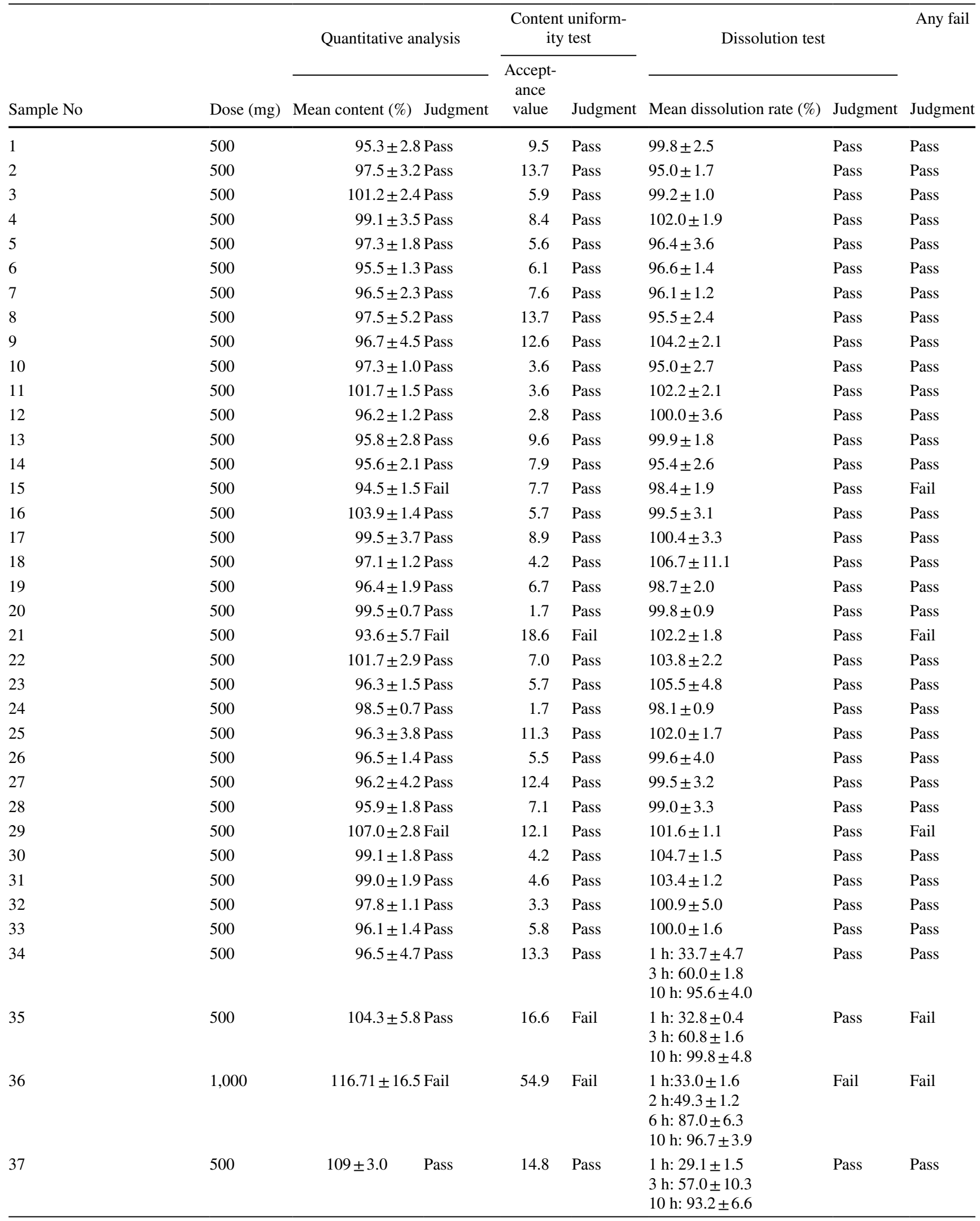


Table 4 (continued)

\begin{tabular}{|c|c|c|c|c|c|c|c|}
\hline \multirow[b]{2}{*}{ Sample No } & \multirow[b]{2}{*}{ Dose (mg) } & Quantitative analysis & \multicolumn{2}{|c|}{$\begin{array}{l}\text { Content uniform- } \\
\text { ity test }\end{array}$} & \multicolumn{2}{|l|}{ Dissolution test } & \multirow{2}{*}{$\begin{array}{l}\text { Any fail } \\
\text { Judgmen }\end{array}$} \\
\hline & & Mean content (\%) Judgment & $\begin{array}{c}\text { ance } \\
\text { value }\end{array}$ & Judgment & Mean dissolution rate $(\%)$ & Judgment & \\
\hline 38 & 750 & $100.5 \pm 8.7$ Pass & 21.1 & Fail & $\begin{array}{l}1 \mathrm{~h}: 30.5 \pm 1.4 \\
2 \mathrm{~h}: 46.2 \pm 5.3 \\
6 \mathrm{~h}: 83.4 \pm 4.1 \\
10 \mathrm{~h}: 94.7 \pm 2.2\end{array}$ & Pass & Fail \\
\hline 39 & 500 & $104.3 \pm 2.8$ Pass & 9.6 & Pass & $\begin{array}{l}1 \mathrm{~h}: 35.8 \pm 4.8 \\
3 \mathrm{~h}: 63.9 \pm 5.9 \\
10 \mathrm{~h}: 98.6 \pm 2.8\end{array}$ & Pass & Pass \\
\hline 40 & 500 & $99.2 \pm 7.5$ Pass & 23.0 & Fail & $\begin{array}{l}1 \mathrm{~h}: 38.7 \pm 1.4 \\
3 \mathrm{~h}: 68.6 \pm 3.3 \\
10 \mathrm{~h}: 97.6 \pm 2.2\end{array}$ & Fail & Fail \\
\hline
\end{tabular}

import of medicines to patients and consumers, as well as monitoring advertisements for medicine promotion on the Internet [25, 26]. For unregistered/unlicensed medicines, the possibility of compassionate use cannot be excluded. However, the use of unregistered/unlicensed medicines should be avoided for general consumers. The unrecognized/unlicensed drugs can be obtained in Japan via the Internet; this situation may exist in other countries as well. To prevent adverse outcomes caused by personally imported drugs, it is necessary to raise awareness to ensure that consumers do not carelessly import pharmaceutical products.

We obtained one Japanese product (No. 32) among the products examined in this study (Table 1). This is one of the problems of the personal import of medicines in Japan. Medicines manufactured in Japan will be delivered from the manufacturing company to hospitals and pharmacies through domestic wholesalers and ultimately delivered to consumers. However, the availability of a Japanese product online suggested that an unauthorized distribution channel of drugs exists. This channel differed from the original distribution channels of imported agents. Because of the existence of unauthorized distribution channels, the quality of the medicine can be altered because of improper transportation and storage even if the product was manufactured in Japan.

Although metformin is a prescription medicine in Japan, online wholesalers do not confirm prescriptions. Concerning the outer packaging (Table 1), six box-packaged samples from Singapore and one sample from India in blister packaging were deemed genuine. However, because of insufficient information from the manufacturer or distributor on the package and the low response rate for the authenticity survey, we cannot identify and summarize the rules and basis for judging the authenticity or quality of the products. It was difficult to determine whether the labeled manufacturing or distributing country on the package was accurate because the authenticity of samples was not determined.
Visual observation confirmed that several samples had physical cracks or stains. Although all of these samples passed quality testing, the cracks or stains may have been caused by lower-quality excipients or improper manufacturing practices, or may have been introduced during transportation because of defective packaging. These deficiencies might affect the health of consumers.

Consumers who obtain medicines via personal import agencies without guidance from a doctor or pharmacist possibly refer to the package and instructions of the product when using the drugs. However, the packaging and insert for $98 \%$ of the purchased samples were not written in Japanese, and inserts and packaging materials written in foreign languages do not provide sufficient information to patients. Additionally, the dose described in the insert of one sample did not match the actual dose. Inappropriate drug use may result in side effects, which can threaten patients' health.

The online price of one 500-mg metformin tablet was higher than that from a regular Japanese medical institution (Fig. 1). Therefore, there are no cost advantages to purchasing drugs online. None of the websites required a prescription to purchase metformin and unauthorized/unlicensed doses could be obtained. This encourages the import of drugs that can cause health effects associated with improper use.

In total, four and five samples failed quantitative analysis and CU testing, respectively (Table 4). If the content of the active ingredient is insufficient or inconsistent, therapeutic efficacy cannot be achieved. Long-term continuous use of ineffective drugs may increase the risks of complications such as retinopathy, nephropathy, neurological disorders, and heart disease.

For the dissolution test, two samples (both extendedrelease/sustained-release tablets) failed specifications (Table 4). The sustained-release system of two samples was broken, and appropriate sustained release was not 
observed. However, because the result only slightly deviated from the pharmacopeia standard, the products are not expected to cause a rapid increase in blood glucose concentrations, which increases the risks of adverse outcomes.

One limitation of the study was that we only tested 40 samples and evaluated 24 websites. The research object was only one drug, and the results do not reflect the quality of all medicines available online. Expanding the number of samples may provide more comprehensive information and permit more relevant discoveries. Another limitation was that most manufacturers did not complete the authenticity survey, and thus, we could not verify the authenticity of most products. However, the circulation of low-quality medicines on the Internet was confirmed. This study indicates the need for consumers to avoid purchasing medicines on the Internet. Additionally, the findings also revealed that active cooperation between manufacturers and regulatory authorities is necessary for improving the quality of medicines in circulation.

\section{Conclusions}

This study clarified that metformin tablets of poor-quantity and unregistered/unlicensed doses can be personally imported into Japan without a prescription via the Internet. It is difficult to judge the quality of medicines based on the outer packaging. Because medicines can easily be imported via the Internet, consumers must be aware of the existence of falsified or poor-quantity medicines and the dangers of personal import. Additionally, relevant regulatory authorities should provide consumers with information and warnings to increase awareness of this issue. Moreover, it may be necessary to monitor or block illegal personal import agencies or senders to ensure the safety of consumers.

\section{Acknowledgements}

We thank Apotex Pty Ltd, CIPLA LTD, and Towa Pharmaceutical Co., Ltd. for evaluating the authenticity data. We thank Joe Barber Jr., PhD, from Edanz Group (https://en-author-services.edanzgroup.com/ac) for editing a draft of this manuscript.

\section{Author Contributions}

SZ: Conceptualization, methodology, validation, formal analysis, investigation, data curation, writing-original draft, visualization. NY: conceptualization, methodology, formal analysis, investigation, resources, writing - review \& editing, supervision, funding acquisition. $\mathrm{RM}$ : investigation. KK: conceptualization, methodology, investigation, resources, writing — review \& editing, supervision, funding acquisition. HT: formal analysis, writing -review \& editing.

\section{Funding}

This research was supported by the Health Labor Sciences Research Grant of Japan (H20-Iyaku-Ippan-023) from the Ministry of Health, Labour and Welfare of Japan.

\section{Compliance with Ethical Standards}

\section{Conflict of interest}

The authors declare no potential conflicts of interest with respect to the research, authorship, and/or publication of this article.

\section{Open Access}

This article is licensed under a Creative Commons Attribution 4.0 International License, which permits use, sharing, adaptation, distribution and reproduction in any medium or format, as long as you give appropriate credit to the original author(s) and the source, provide a link to the Creative Commons licence, and indicate if changes were made. The images or other third party material in this article are included in the article's Creative Commons licence, unless indicated otherwise in a credit line to the material. If material is not included in the article's Creative Commons licence and your intended use is not permitted by statutory regulation or exceeds the permitted use, you will need to obtain permission directly from the copyright holder. To view a copy of this licence, visit http://creativecommons.org/licenses/by/4.0/.

\section{References}

1. American Diabetes Association. Diagnosis and classification of diabetes mellitus. Diabetes Care. 2009;32(1):S62-7. https://doi. org/10.2337/dc09-S062.

2. NCD Risk Factor Collaboration (NCD-RisC). Worldwide trends in diabetes since 1980: a pooled analysis of 751 population-based studies with 4.4million participants. Lancet. 2016; 387:15131530. https://doi.org/10.1016/S0140-6736(16)00618-8

3. Cho NH, Shaw JE, Karuranga S, Huang Y, et al. IDF Diabetes Atlas: global estimates of diabetes prevalence for 2017 and projections for 2045. Diabetes Res Clin Pract. 2018;138:271-81. https ://doi.org/10.1016/j.diabres.2018.02.023.

4. Viollet B, Guigas B, et al. Cellular and molecular mechanisms of metformin' an overview. Clin Sci. 2012;122(6):253-70. https:// doi.org/10.1042/CS20110386.

5. Eikawa S, Nishida M, Mizukami S, et al. Immune-mediated antitumor effect by type 2 diabetes drug metformin. PNAS. 2015;112(6):1809-14. https://doi.org/10.1073/pnas.1417636112.

6. Evans JM, Donnelly LA, et al. Metformin and reduced risk of cancer in diabetic patients. BMJ. 2005;330:1304. https://doi. org/10.1136/bmj.38415.708634.F7.

7. Muri L, Le ND, Zemp J, et al. Metformin mediates neuroprotection and attenuates hearing loss in experimental pneumococcal meningitis. J Neuroinflamm. 2019;16:156.

8. WHO Regulation: Definitions of Substandard and Falsified (SF) Medical Products, 29 May 2017, 2017 https://www.who.int/medic ines/regulation/ssffc/definitions/en/.Accessed 12 November 2020

9. Gyanwali P, Humagain BR, Aryal KK, Pandit A, et al. Surveillance of quality of medicines available in the Nepalese market: a study from Kathmandu Valley. J Nepal health Res Coinc. 2015;13(31):233-40. 
10. Ndichu TE, et al. Evaluating the quality of antihypertensive drugs in Lagos State, Nigeria. PLoS ONE. 2019;14(2):e0211567. https ://doi.org/10.1371/journal.pone.0211567.

11. Caudron JM, Ford N, Henkens M, et al. Substandard medicines in resource- poor settings: a problem that can no longer be ignored. 2008; 13(8):1062-1072. https://doi.org/https://doi.org/10.111 1/j.1365-3156.2008.02106.x

12. Kosugi A, Sanami Y, Hanada M, et al. Report: Sample collection and testing of target essential medicines from the private sector markets in four areas in Cambodia, to ascertain their quality based on selected criteria. 2014; WHO Registration 2013/346475-0

13. Johnston A, Holt WD. Substandard Drugs: a potential crisis for public health. Br J Clin Pharmacol. 2014;78(2):218-43.

14. Lee KS, Yee SM, et al. Combating Sale of counterfeit and falsified Medicine Online: a Losing Battle. Front Pharmacol. 2017;8:268. https://doi.org/10.3389/fphar.2017.00268.

15. Jack A. Can anyone stop the illegal sale of medicines online? BMJ. 2016. https://doi.org/10.1136/bmj.i1317.

16. Inspection and Guidance Division PaMSB, Ministry of Health and Welfare, Japan. Importing or bringing medication into Japan for personal use [in Japanese]. https://www.mhlw.go.jp/stf/seisa kunitsuite/bunya/kenkou_iryou/iyakuhin/kojinyunyu/topics/tp010 401-1.html. Accessed 12 Nov 2020.

17. Takanashi H, Okazawa H, Aihara F, Koga T, Hashimoto K. Theme: Personal import of drugs that risk lurks: danger not only for counterfeit medicines. Jpn J Soc Pharm. 2016;35:108-16 ([In Japanese]).

18. Yoshida N, Numano M, Nagasaka Y, et al. Study on health hazards through medicines purchased on the Internet: across-sectional investigation of the quality of anti-obesity medicines containing crude drugs as active ingredients. BMC Complement Altern Med. 2015;15:430. https://doi.org/10.1186/s12906-015-0955-2.

19. Zhu S, Yoshida N, Kimura K, et al. Falsified vardenafil tablets available online. J Pharm Biomed Anal. 2020;177:112872. https ://doi.org/10.1016/j.jpba.2019.112872.

20. Sanada T, Yoshida N, Matushita R, et al. Falsified tadalafil tablets distributed in Japan via the internet. Forensic Sci Int. 2020;307:110143. https://doi.org/10.1016/j.forsciint.2020.11014 3.

21. Rahman MS, Yoshida N, Sugiura S, Tsuboi H, Keila T, et al. Quality of omeprazole purchased via the Internet and personally imported into Japan: comparison with products sampled in other Asian countries. Trop Med Int Health. 2018;23:263-9. https://doi. org/10.1111/tmi.13028.

22. Act on Specified Commercial Transactions, Act No. 50, 2019 [in Japanese]

23. Act on Securing Quality, Efficacy and Safety of Products Including Pharmaceuticals and Medical Devices, 1960 [in Japanese]

24. U.S. Pharmacopeia National Formulary, USP 37, NF 32 Volume3, 2014.

25. Ministry of Health, Labour and Welfare, Japan. For those who want to purchase medicines from overseas. [in Japanese] https:// www.mhlw.go.jp/stf/seisakunitsuite/bunya/kenkou_iryou/iyaku hin/kojinyunyu/index.html. Accessed 12 November 2020.

26. Chief of Pharmaceutical and Medical Safety Bureau MoHaW, Japan. Guidance and control of personal import agencies. [in Japanese]. https://www.mhlw.go.jp/kinkyu/diet/tuuchi/0828-4.html. Accessed 12 November 2020. 